\title{
CONSOLIDAÇÃO E CODIFICAÇÃO EM DIREITO CIVIL: BASES \\ CONCEITUAIS E EXPERIÊNCIAS SULAMERICANAS
}

\author{
CONSOLIDATION AND CODIFICATION IN CIVIL LAW: CONCEPTUAL BASES AND \\ SOUTH AMERICAN EXPERIENCES
}

Fabio Queiroz Pereira ${ }^{1}$

\begin{abstract}
Resumo: O presente artigo busca compreender as bases conceituais dos termos consolidação e codificação, pois, apesar do amplo e comum uso das duas técnicas legislativas, não há consenso doutrinário em relação às suas características e ao alcance de seus usos. Foram apresentadas as similitudes e as diferenças de tratamento dado aos termos, buscando dialogar, principalmente, com as percepções do jurista italiano Mario Viora, em clássica obra sobre o tema. Em seguida à referida exposição, intentou-se identificar as particularidades existentes nas construções teóricas e nas experiências de dois países sul-americanos: Brasil e Chile. Para tanto, foram estudas as obras de Augusto Teixeira de Freitas e de Andrés Bello, verificando-se que a concepção da técnica consolidadora aplicada ao direito civil foi dotada de características próprias. Nesse sentido, foi realizado exercício comparativo para compreender os fundamentos das particularidades e para decompor o problema jurídico conceitual. Averiguou-se, assim, que, para ambos os juristas, no plano teórico, a técnica consolidadora foi pensada como exercício preparatório para a feitura de uma codificação, afastando-se da concepção até então existente, no âmbito da ciência jurídica europeia. Apesar das diferenças na consecução das tarefas de consolidação e de codificação, uma das comuns preocupações de Freitas e de Bello parece ter sido a preservação de uma tradição jurídica, sem que fosse realizada uma brusca ruptura com o anterior corpo normativo vigente.
\end{abstract}

Palavras-chave: consolidação, codificação, técnicas legislativas, experiências sulamericanas.

Abstract: This article seeks to understand the conceptual basis of the terms consolidation and codification for, despite the broad and common use of the two legislative techniques, there is no doctrinal consensus with respect to their characteristics and the scope of their uses. The similarities and the differences in treatment of terms were presented, seeking to dialogue, especially with the perceptions of the Italian jurist Mario Viora in his classic work on the subject. Following the aforementioned account, an attempt was made to identify the particularities in theoretical constructs and experiences of two South American countries: Brazil and Chile. For that, the works of Augusto Teixeira de Freitas and Andrés Bello were studied, verifying that the design of the consolidator technique applied to civil law was endowed with its own characteristics. In this sense, a comparative exercise to understand

\footnotetext{
1 Doutor em Direito Civil pela Universidade Federal de Minas Gerais. Mestre em Direito Civil pela Universidade de Coimbra. Graduado em Direito pela Universidade Federal de Minas Gerais. Professor de Direito Civil na Universidade Federal de Minas Gerais.
} 
the fundamentals of the peculiarities and to decompose the conceptual legal problem was performed. Therefore, it was found that for both lawyers the consolidator technique was designed as a preparatory exercise for the making of a coding away from the conception hitherto existing within the European legal science. Despite differences in the achievement of the consolidation and coding tasks, one of the common concerns of Freitas and Bello appears to have been the preservation of a legal tradition, one that does not abruptly break with the previous existing regulatory body.

Keywords: consolidation, codification, legislative techniques, South American experiences.

\section{INTRODUÇÃO}

A crescente complexidade das relações sociais conduz ao paralelo fenômeno do aumento do número de leis que buscam regular as condutas em uma dada coletividade. No entanto, o excesso de instrumentos legislativos, não raramente, concretiza um verdadeiro caos, marcado pela insegurança quanto ao direito aplicado e pela incoerência encontrada no corpo das normas a serem utilizadas nos casos concretos. Nos contextos em que se verifica essa verdadeira inflação legislativa, passa a tomar o centro das preocupações a busca pela organização e sistematização dos instrumentos vigentes. Esse fenômeno parece repetir-se no tempo e alcançar variados ordenamentos jurídicos. Como sustentado por João Baptista Villela (1988, p. 241):

[...] a aspiração de saneamento formal da legislação converteu-se em fenômeno típico do Estado moderno, reduzido, em certa medida, a um aprendiz de feiticeiro, que se perde nos labirintos por ele mesmo abertos, que se enleia no cipoal que fez crescer, que sufoca na selva selvaggia dos seus produtos, que se revela, enfim, perplexo e impotente ante o crescimento e desgoverno de sua própria criatura.

Diante de uma gama imensa de leis e instrumentos normativos, busca-se dotar o corpo de normas de critérios organizacionais mínimos que gerem a necessária segurança ao direito e possibilitem ao jurista um fácil manuseio dos dispositivos a serem utilizados no plano prático. Concernentemente ao direito civil, o caráter imperativo da referida tarefa apresenta-se de modo ainda mais agravado, tendo em vista a sua forte influência nas relações privadas cotidianas.

Para elaborar e organizar esse corpo de normas, por outro lado, podem ser utilizadas diferentes técnicas legislativas, dentre as quais se destacam a consolidação e a codificação. Como se verá, trata-se de fenômenos legislativos dotados de determinadas características 


\section{RFD}

peculiares, que, no entanto, não apresentam uniformidade em seus enquadramentos teórico-dogmáticos.

Interessante observar que, na experiência sul-americana, dois países destacam-se pela teorização ou pelo efetivo uso das duas técnicas no processo de formação de seus corpos normativos de direito civil, quais sejam Brasil e Chile. No primeiro país, a insegurança jurídica gerada pela multiplicidade de normas apresentou especial relevo no contexto pós-independência. Ao romper com a metrópole, deveria o país seguir rumos próprios, identificando as normas que teriam vigência ou produzindo novos instrumentos normativos. Foram, assim, demasiadamente relevantes os trabalhos empreendidos por Augusto Teixeira de Freitas, jurista incumbido da elaboração da Consolidação das Leis Civis e, posteriormente, autor do projeto de código civil, conhecido como Esboço. Já no Chile, diante de similar conjuntura, destaca-se o trabalho desenvolvido por Andres Bello, autor do projeto que deu origem ao Código Civil da República do Chile, do ano de 1855. O aludido jurista acreditava na adequação da técnica consolidadora como etapa revisional para alcance de uma adequada codificação, embora, a realidade tenha acabado por consagrar diretamente o Código, sem que se tenha conhecido qualquer consolidação.

Desse modo, o presente ensaio busca compreender os conceitos de consolidação e de codificação para, em seguida, verificar as particularidades identificadas nas construções teóricas e nos trabalhos empreendidos por Teixeira de Freitas e por Andres Bello. A concepção e a aplicação das referidas técnicas parecem dotadas de características próprias e o exercício comparativo mostra-se como adequado instrumento para compreender as justificativas e fundamentos para tanto.

\section{AS CONSOLIDAÇÕES}

Com a evolução de um grupo social normas consuetudinárias são criadas no esforço de regular as condutas dos indivíduos. Como decorrência direta desse fato, os costumes eleitos como regras tendem a se materializar em normas escritas, de modo a fornecer um maior grau de certeza quanto à aplicação do direito. Segundo Mario Viora (1967, p. 1), “a população sente a necessidade de redigir um corpo escrito de normas consuetudinárias, de 
modo que essas possam ser rapidamente conhecidas e respeitadas por todos e que não sejam, por outro lado, esquecidas" 2 .

Esse corpo de normas, no entanto, tende a se tornar cada vez mais complexo, e o surgimento paulatino de um excesso de instrumentos legais origina uma conjuntura confusa, propícia à contradição e à desordem no momento de aplicação do direito. Diante desse contexto, surge a preocupação com a organização e o funcionamento do sistema. Observa-se um verdadeiro clamor social no sentido de se adequar as normas às necessidades práticas da população.

As consolidações podem ser compreendidas como resultado desse processo, materializando uma tentativa de ordenar o direito vigente. Elaborar uma consolidação é, assim, um trabalho que se concretiza com os olhos voltados para o passado. A organização do ordenamento jurídico faz-se por meio da pesquisa e identificação do direito a ser aplicado. Trata-se, em verdade, de um exercício sintético que busca ordenar as normas em vigência, baseando-se em determinados critérios.

Importante traçar a diferenciação entre consolidação e compilação. Enquanto a primeira é marcada pelo caráter sistemático, a segunda materializa uma simples ordenação de instrumentos, sem que seja adotada qualquer ideia de coerência interna do corpo de normas. Uma compilação apoia-se, habitualmente, em simples critério cronológico ou material agrupando os textos legais, sem preocupação com contradições ou omissões ${ }^{3}$.

A consolidação, no entanto, revela-se como técnica de organização de normas dotada de maior complexidade e sofisticação. Faz-se necessária a análise de variados textos, pautada em critérios racionais e sistêmicos, que possibilitem a elaboração de um conjunto ordenado de regras. Nesse sentido, textos legislativos podem ser suprimidos ou substituídos, desde que tal ocorrência esteja pautada nos critérios inicialmente formulados. De acordo com João Baptista Villela (1988, p. 246), “excluída a prática do arbítrio, o consolidador é livre para descobrir combinações, tanto mais adequadas quanto melhor respondam aos novos anseios do sistema de direito positivo e tanto mais fecundas quanto

\footnotetext{
${ }^{2}$ No original: "Il popolo [...] sente il bisogno di redigere in iscritto il corpo delle norme consuetudinarie, affinchè esse possano da tutti essere agevolmente conosciute e rispettate, e non siano d'altra parte dimenticate". (Tradução livre).

${ }^{3}$ Sobre as Ordenações do Reino de Portugal, Giordano Bruno Soares Roberto enquadra-as como simples compilações: "Todas as três compilações se caracterizavam pelo apego comodista ao Direito Romano e ao Direito Canônico, além das inúmeras falhas e contradições. Em todas, inclusive na última, nascida já no século XVII, as opiniões de Acúrsio e de Bártolo eram consideradas regras subsidiárias e deveriam ser seguidas pelo seu valor extrínseco e não apenas quando fossem razoáveis" (ROBERTO, 2003. p. 54).
} 
mais capazes sejam de ultrapassá-lo". Trata-se, assim, de uma apreciação da legislação passada, pautada em elementos presentes, e voltada para a ordenação dos acontecimentos futuros. A escolha dos textos vigentes e sua adequação dentro de uma conjuntura sistemática revelam-se como os pontos centrais em que se funda uma consolidação de direito. São essas combinações que permitirão que o sistema de normas vigentes ultrapasse o corpo desordenado de regras identificado preteritamente.

\section{AS CODIFICAÇÕES}

A técnica codificadora, por outro lado, é atividade que se volta para o futuro. Ao realizar uma codificação, o jurista não está adstrito aos elementos normativos do passado. Sua liberdade é bem mais ampla e permite a construção de novas figuras de diferentes contornos jurídicos. Segundo Caio Mário da Silva Pereira (2010, p. 64), “codificar o direito é coordenar as regras pertinentes às relações jurídicas de uma só natureza, criando um corpo de princípios, dotados de unidade e deduzidos sistematicamente". Assim, um código não se trata apenas de uma soma de normas, mas sim de um corpo dotado de unidade e construído sob a estrutura de verdadeiro sistema de direito.

De fato, a própria ideia de sistema já traz em si a necessária identificação da unidade. Não é possível pensar em um sistema que não se paute no critério de unidade. Sobre a temática, afirma Claus-Wilhelm Canaris (2002, p. 12):

\footnotetext{
Há duas características que emergem em todas as definições de sistema: a da ordenação e a da unidade. [...] No que respeita, em primeiro lugar, à ordenação, pretende-se com ela exprimir um estado de coisas intrínseco racionalmente apreensível, isto é, fundado na realidade. No que toca à unidade, verifica-se que este factor modifica o que resulta já da ordenação, por não permitir uma dispersão numa multitude de singularidades desconexas, antes devendo deixá-las reconduzirse a uns quantos princípios fundamentais.
}

Alguns doutrinadores, no entanto, perfilham um conceito diverso do que seja uma codificação. Nesse sentido, por exemplo, identifica-se o pensamento de John Gilissen (2008, p. 448), para quem “a ideia de código corresponde a uma compilação de normas jurídicas de origem legislativa ou, por vezes, doutrinal, tendentes a um melhor conhecimento do direito e uma maior segurança jurídica" (GILISSEN, 2008, p. 448). A título de exemplo, em sua obra, Gilissen aponta as codificações romanas ou mesmo as Ordenações Afonsinas, Manuelinas e Filipinas como corpos de normas que atendem à ideia 
de um código (Cf. GILISSEN, 2008, p. 449). Não prepondera, no entanto, essa concepção doutrinária.

Na verdade, a compreensão do que seja uma codificação não é algo que demonstre entendimento pacífico até os dias de hoje. No entanto, é inegável que os elementos centrais que descrevem o que realmente é um código remetem-se ao pensamento jus-filosófico do século XVIII. Trata-se, assim, de um fenômeno da modernidade que surge em decorrência do pensamento iluminista europeu. Sobre essa conexão, R. C. van Caenegem (2000, p. 163) sustenta que:

\begin{abstract}
Os velhos costumes e os livros autorizados deveriam ser substituídos por um novo direito livremente concebido pelo homem moderno, cujo único princípio diretor fosse a razão. Esse novo direito deveria estar isento de qualquer obscurantismo. Ele constituiria um sistema claro e certo, compreensível para o povo, pois, de agora em diante, o direito deveria estar a serviço do povo. Para alcançar esse objetivo, era preciso preencher duas condições. A primeira era material: a criação de um novo sistema jurídico baseado num novo corpo de fontes; a segunda era formal: uma nova técnica deveria ser desenvolvida para assegurar a aplicação na prática do novo direito. A primeira condição foi preenchida pelo direito natural, a segunda pela legislação, em particular pelos códigos nacionais introduzidos em todo o continente europeu.
\end{abstract}

Assim, para a substituição dos velhos costumes pelo novo direito fez-se imperiosa a elaboração das codificações e, nesse cenário, os códigos jusnaturalistas apresentam-se, comumente, como instrumentos conexos às transformações revolucionárias. Não obstante o surgimento do Código da Áustria e do Código da Prússia, produtos do despotismo esclarecido, o maior e mais influente modelo de codificação é materializado no Código Civil francês, de $1804^{4}$. A obra de Napoleão Bonaparte é comumente vista como uma adequação dos valores tradicionais do direito francês com os anseios gerados pelo período revolucionário. Elaborado por juristas práticos, o Code Napoleón alcançou o objetivo de promulgação de uma nova ordem jurídica, mesmo que houvesse clara ligação com os institutos clássicos presentes no direito francês.

Quanto às características de uma codificação, baseando-se em Norberto Bobbio, Giordano Bruno Soares Roberto apresenta um rol de elementos a serem identificados. De

\footnotetext{
${ }^{4}$ Franz Wieacker (2004, p. 365) assevera que "a ligação do jusracionalismo com o iluminismo produziu, primeiro nos estados absolutos do centro e do sul da Europa, depois na Europa ocidental após o processo revolucionário francês, uma primeira grande onda das codificações modernas. Apesar do carácter muito facetado das circunstâncias do seu aparecimento, estes códigos apresentam um idêntico perfil espiritual. Distinguem-se de todas as anteriores redacções de direitos desde logo pelo facto de que eles não fixam, ordenam ou melhoram direito já existente; nem pretendem completá-lo (como, por exemplo as Ordonnances francesas e as Reformationen alemãs do séc. XVI); eles dirigem-se antes a uma planificação global da sociedade através da reordenação sistemática e inovadora da matéria jurídica".
} 


\section{RFD}

acordo com o autor, a primeira característica de um código deveria ser sua completitude, uma vez que seu objetivo seria abranger todo o direito de um país ou uma área completa do Direito. A segunda qualidade de uma codificação seria a clareza da redação, que permitiria sua perfeição formal. A terceira característica seria a brevidade, transparecendo concisão, não permitindo o texto descer a minúcias, mas dando as diretrizes básicas do sistema. O quarto predicado estaria na acessibilidade, permitindo a linguagem do código ser acessível a todos os cidadãos. E, por fim, uma codificação deveria aspirar permanência, devendo para tanto ser rígida, dificultando a ocorrência de modificações (ROBERTO, 2003, p. 31-32). Assim, essas características, somadas ao arcabouço sistêmico, apresentam-se como elementos centrais e concretizadores de um apropriado código de normas. Importa, contudo, compreender as diferenças estruturais existentes entre a prática consolidadora e a técnica da codificação.

\section{CONSOLIDAÇÕES E CODIFICAÇÕES: ELEMENTOS DISTINTIVOS}

Em uma análise generalista, Ricardo Luis Lorenzetti discorre sobre algumas diferenças existentes entre as consolidações e as codificações. Para o autor, as consolidações pretendem reproduzir o direito vigente, sem modificá-lo, objetivando continuidade ou melhoria. De maneira oposta, a codificação pretende uma ruptura, criando nova regulamentação substitutiva. No aspecto formal, as consolidações gerariam insegurança, uma vez que não se sabe ao certo qual o direito a ser aplicado, e seriam, por consequência, incognoscíveis para o cidadão. Já os códigos permitiriam segurança, traduzida em uma sequência ordenada de artigos, e concretizariam também maior acessibilidade ao seu texto. As consolidações basear-se-iam em critérios cronológicos e casuísticos, estando ausentes os enunciados gerais e abstratos. As codificações, por outro lado, estariam fundadas em axiomas principiológicos, restringindo o campo de atuação do intérprete. Por fim, Lorenzetti aponta o direito civil codificado como autossuficiente, enquanto o direito baseado na consolidação não prescindiria da busca de outras fontes jurídicas (LORENZETTI, 1998, p. 42-43).

Como colocado por Giordano Bruno Soares Roberto (2003, p. 31), os "delineamentos [dos referidos critérios] são algo simplistas e até exagerados em alguns aspectos". No entanto, é possível identificar na exposição de Lorenzetti alguns dos aspectos 
centrais da diferenciação entre as técnicas de consolidação e de codificação, como o retorno a um direito vigente e a busca de um direito novo. No que diz respeito aos axiomas, as afirmações de Lorenzetti não parecem as mais adequadas. Não há nenhum empecilho a que um texto consolidado seja baseado em uma sistemática que busque a sua unidade em valores principiológicos. Como se verá, a Consolidação das Leis Civis, elaborada por Augusto Teixeira de Freitas, é um exemplo de aplicação da técnica consolidadora que tem por base uma divisão sistemática calcada em valores sólidos.

Uma das obras mais paradigmáticas sobre o tema foi desenvolvida pelo italiano Mario Viora. Com um pequeno trabalho, elaborado inicialmente em 1928 e intitulado "Consolidazioni e codificazioni: contributo alla storia della codificazione", o autor buscou delimitar e distinguir as categorias consolidação e codificação. Tratava-se de uma preocupação presente naquele tempo, em que variados instrumentos eram denominados como códigos, mas que, até hoje, se revela importante diante da ausência de um entendimento pacífico sobre a aludida diferenciação ${ }^{5}$.

Mario Viora (1967, p. 41-42) chama a atenção para um primeiro e importante ponto de distinção entre as duas categorias: a novidade do material legislativo oferecido pelos códigos. Essa originalidade distingue as codificações modernas das antigas consolidações, que continham apenas material legislativo preexistente. Nesse ponto, é importante destacar que não revela importância o fato de os codificadores levarem em consideração as normas antigas. Na verdade, os códigos pretendiam ser uma elaboração nova, cujas normas, longe de serem tratadas como na antiga tradição jurídica, são inspiradas por critérios vários encontrados na mente do legislador. Os códigos da Modernidade, em razão dos princípios em que buscavam inspiração, objetivavam a apresentação de um sistema novo de direito, que buscava ser considerado divergente do precedente sistema de direito comum, e quase antitético a esse, vindo, no momento próprio, a substituí-lo completamente.

Ainda segundo Viora (1967, p. 43), a técnica codificadora trouxe vantagens novas e indiscutíveis. Uma delas materializava-se na possibilidade de manejo dos corpos de normas

\footnotetext{
${ }^{5}$ Sobre a proposição de Mario Viora, sustenta Ugo Petronio (1984, p. 707): “Nesse ponto, me parece que se imponha a releitura de alguns passos de Viora, que provavelmente limitou-se a propor, na ótica naturalística e positivista que o inspirava, um instrumento para classificar, talvez de modo adequado, as diversas coleções de leis que se seguiram no tempo e que foram muitas vezes rotuladas como códigos". No original: "A questo punto mi sembra che s'imponga la rilettura di qualche passo di Viora, il quale probabilmente si era limitato a proporre, nell'ottica naturalistica e positivistica che lo ispirava, uno strumento per classificare, magari alla buona, le diverse raccolte di leggi che si erano susseguite nel tempo e che spesso erano tutte etichettate codici". (Tradução livre)
} 
correspondentes às grandes divisões de direito. As normas passaram a ser subdivididas em uma hierarquia de títulos, livros e parágrafos, dotados cada um de uma série de disposições elementares marcadas por uma individualidade própria. Mesmo a destinação exclusiva da codificação ao regramento de um ramo determinado do direito era uma novidade. Nas consolidações verificava-se, lado outro, um conjunto de normas pertinente aos mais diversos ramos do direito. Por fim, a arquitetura dos códigos, a concisão e a clareza de sua linguagem, constituíram um melhoramento essencial do precedente estado de coisas.

Desse modo, adotando-se a concepção exposta por Mario Viora, os códigos modernos romperam com a técnica legislativa anterior, qual seja a da consolidação. O que marca essencialmente uma codificação são os elementos que revelam a sua originalidade frente ao pretérito direito identificado na Europa. Diante de suas novas vantagens, a sistematização por meio dos códigos acaba por romper com a anterior tradição de se utilizar da categoria consolidação. Percebe-se, assim, entendimento que materializa caráter evolutivo. Os códigos revelar-se-iam como um sistema em substituição às ultrapassadas consolidações de normas jurídicas.

\section{CONSOLIDAÇÃO E CODIFICAÇÃO NA OBRA DE AUGUSTO TEIXEIRA DE FREITAS}

Analisando o ordenamento jurídico brasileiro, tem-se a Consolidação das Leis Civis, elaborada por Teixeira de Freitas, como o principal modelo de concretização da técnica consolidadora ${ }^{6}$. As concepções de consolidação e de codificação ganharam novos desenhos no processo de formação legislativa no Brasil pós-independência. Os trabalhos de Teixeira de Freitas, na elaboração da Consolidação das Leis Civis, denotam uma percepção diversa do que seria realmente uma consolidação.

Com a independência do Brasil, em setembro de 1822, surgiu uma nova nação sem que se verificasse um original arcabouço legislativo a sustentá-la. Fruto de uma ruptura, restou ao nosso país a utilização das leis da antiga metrópole como forma de possibilitar um

\footnotetext{
${ }^{6}$ Uma das mais famosas consolidações desenvolvidas no Brasil é a Consolidação das Leis do Trabalho (CLT), instrumento ainda vigente. Não obstante a sua designação, parte da doutrina compreende que, na verdade, se trata de um verdadeiro Código Trabalhista. Nesse sentido, Mauricio Godinho Delgado sustenta que "o modelo justrabalhista então estruturado reuniu-se, anos após ano, em um único diploma normativo, a Consolidação das Leis do Trabalho (Decreto-lei n. 5.452, de 1.5.1943). Embora o nome reverenciasse a obra legislativa anterior (consolidação), a CLT, na verdade, também alterou e ampliou a legislação trabalhista existente, assumindo, desse modo, a natureza própria de um código do trabalho" (DELGADO, 2004. p. 112).
} 
mínimo de segurança jurídica. Nesse contexto, foi publicada a Lei de 20 de outubro de 1823, que previa em seu art. $1^{\circ}$ :

\begin{abstract}
As Ordenações, Leis, Regimentos, Alvarás, Decretos, e Resoluções promulgadas pelos Reis de Portugal, e pelas quaes o Brazil se governava até o dia 25 de Abril de 1821, em que Sua Magestade Fidelissima, actual Rei de Portugal, e Algarves, se ausentou desta Côrte; e todas as que foram promulgadas daquella data em diante pelo Senhor D. Pedro de Alcantara, como Regente do Brazil, em quanto Reino, e como Imperador Constitucional delle, desde que se erigiu em Imperio, ficam em inteiro vigor na parte, em que não tiverem sido revogadas, para por ellas se regularem os negocios do interior deste Imperio, emquanto se não organizar um novo Codigo, ou não forem especialmente alteradas.
\end{abstract}

Pode-se imaginar a existência de um ambiente extremamente confuso no que se relaciona à aplicação da legislação no Brasil. Em paralelo às Ordenações Filipinas, estava vigendo uma vasta legislação extravagante ${ }^{7}$.

Em 1824, o país começa a se organizar politicamente com a promulgação da Constituição do Império. Além dos necessários elementos de coordenação estatal, em seu texto, faz-se a previsão expressa de elaboração de um trabalho codificador. Constata-se a seguinte disposição em seu artigo 179: "Organizar-se-ha quanto antes um Codigo Civil, e Criminal, fundado nas solidas bases da Justiça, e Equidade". Não há consenso se se buscava a realização de um código único, envolvendo matéria civil e criminal, ou se deveriam ser elaboradas duas codificações apartadas. A par dessa controvérsia de ordem hermenêutica, o Código Criminal foi publicado em 1830, restando, assim, a materialização de uma codificação civil.

Optou-se, no entanto, por, antes da codificação civil, realizar a consolidação do direito vigente, sendo Teixeira de Freitas o incumbido dessa empreitada. No entanto, não se pode afirmar ao certo qual a razão para a escolha desse caminho. Trata-se de uma opção que pode ter tido como elemento determinante questão de fundo ideológico, como pode ter sido influenciada pela ausência de aporte financeiro suficiente para o desenvolvimento de um Código Civil.

\footnotetext{
${ }^{7}$ Sobre o aludido contexto, João Baptista Villela afirma: "O Estado brasileiro de meados do século passado está longe de recordar os tempos intervencionistas que hoje vivemos. Nos quadros da legislação civil, contudo, pode-se bem imaginar o clima de confusão e o índice de incerteza do direito a que se havia chegado. As Ordenações Filipinas, que continham o núcleo fundamental de disposições sobre a matéria, eram velhas de mais de dois séculos. Já quando de sua promulgação não estavam à altura dos tempos e, de modo algum, se podem considerar um código no sentido que a expressão evoca desde a viragem do século XVIII para o XIX" (VILLELA, 1988, p. 242).
} 
Nos termos do contrato assinado entre Teixeira de Freitas e o Governo Federal, incumbia ao jurista as seguintes tarefas:

\begin{abstract}
$1^{\circ}$ Coligirá e classificará toda a legislação pátria inclusive a de Portugal anterior à Independência do Império, compreendendo, na coleção e classificação, as leis abrogadas ou obsoletas, com exceção das portuguesas que forem peculiares àquele Reino e não contiverem alguma disposição geral estabeleça regra de Direito.

$2^{\circ}$ A classificação guardará as divisões do Direito público ou administrativo privado, assim como as subdivisões respectivas, será feita por ordem cronológica, contendo, porém, índice alfabético por matérias.

$3^{\circ}$ Consolidará toda a Legislação Civil Pátria com as mesmas condições da classificação. Consiste a consolidação em mostrar o último estado da legislação. A Consolidação será feita por títulos e artigos em os quais serão reduzidas a proporções claras e sucintas as disposições em vigor. Em notas correspondentes deverá citar a lei que autoriza a disposição a declarar o costume que estiver estabelecido contra ou além do texto (Cf. MEIRA, 1983, p. 94).
\end{abstract}

As tarefas foram finalizadas em 1857, mas o trabalho de Teixeira de Freitas na realização da Consolidação das Leis Civis é, até hoje, aplaudido, em razão do seu apuro técnico e de sua sistematização. Sobre seu primoroso desenvolvimento, discorre Sílvio Meira (1983, p. 143):

Constitui um extrato fiel das Leis Civis então vigentes, depuradas, aperfeiçoadas. Era um trabalho preparatório para a tarefa maior da codificação, Para bem entender-se o exaustivo esforço a que se dedicou basta contemplar o número considerável de leis extravagantes que vinham se acumulando através dos séculos, ao lado das Ordenações Filipinas de 1604. Era uma imensa teia de leis extravagantes, diz ele, acumuladas no decorrer de dois séculos e meio. Ninguém antes se abalançara à tarefa. Não bastava ler e classificar, era preciso realizar seleção de textos, adaptando-os à realidade brasileira.

A Consolidação das Leis Civis, devido à sua qualidade técnica, alcançou enorme êxito. É interessante observar que, desde a sua publicação, a obra foi apresentada como um trabalho preparatório para a codificação que não detinha a intenção de substituir legislações, mas, sim, de efetuar a preparação para a concretização do Código Civil brasileiro. Desse modo, a Consolidação é assim apresentada pelo próprio Teixeira de Freitas:

A presente publicação é a última parte dos trabalhos preparatórios, que para a reforma da Legislação Civil empreenderá o Governo Imperial. Examinadas as Leis da nossa extensa coleção, distribuídas em suas divisões naturais, explorou-se particularmente a classe das Leis Civis, e delas se apresenta um extrato fiel. É um trabalho de simplificação, que, destinado à grande obra do Código Civil Brasileiro, mal aspira o merecimento de uma codificação provisória (FREITAS, 1857, p. V). 
Assim, o cerne da Consolidação das Leis Civis estava no seu enquadramento enquanto trabalho preparatório. Mas, apesar dessa característica elucidada oportunamente por Teixeira de Freitas, é possível notar uma ambivalência na obra, pois não se tratava apenas de revelar o direito vigente, mas também de preparar o direito futuro (VILLELA, 1988, p. 245). Desse modo, não obstante ser compreendida como uma atividade preliminar, é nítido o caráter sistematizador encontrado em seus textos. A composição do texto é baseada na ideia de sistema, partindo de um amplo grau de generalidade até se alcançar as peculiaridades dos institutos de direito civil (MARTINS-COSTA, 1999, p. 97).

Nesse sentido, a obra está estruturada na dicotomia existente entre direitos pessoais e direito reais. Apoiando-se no direito romano, essa bipartição serviu de guia ao jurista e lhe deu a tônica necessária para fornecer unidade à sua obra ${ }^{8}$. Apesar de ser uma consolidação, a ideia de sistema está inserida em cada uma de suas linhas e, como consequência, é essa característica que permite o apuro técnico encontrado na Consolidação. Nesse contexto, aduz João Baptista Villela (1988, p. 244):

\begin{abstract}
O seu longo e meticuloso exame do método de ordenação é um puro discurso doutrinário, sem qualquer tributo a limites supostamente intransponíveis da legislação positiva. Tendo considerado a diferença entre direitos reais e direitos pessoais a chave de todas as relações civis, fá-la dominar a distribuição da matéria especial. E, do mesmo modo, havendo pressentido a necessidade de um espaço próprio para as disposições comuns, como precursor que foi da allgemeiner Teil, não hesita em garanti-lo.
\end{abstract}

Assim, seja na estruturação ou na busca por uma unidade conceitual, seja na opção pela utilização de uma parte geral, é possível identificar o cuidado com o emprego sistemático da técnica. Além disso, é possível denotar da sua obra uma preocupação, inclusive, com o juízo de constitucionalidade ${ }^{9}$, algo que só pode ser pensado dentro de uma lógica de sistema.

Por outro lado, a tarefa do consolidador, não raro, esbarra na ausência de liberdade para a modificação da ordem jurídica e, assim, a despeito de estar dotado de amplos

\footnotetext{
${ }^{8}$ Sobre a estrutura e unidade da Consolidação das Leis Civis, Judith Martins-Costa discorre: "Ora, o que me parece digno de nota é que uma tal estrutura só seria possível se tivesse como premissa a existência, em cada ser, em cada instituto jurídico, de um princípio primeiro, fundante e verdadeiro, princípio inato, radicado no interior do próprio ser, e do qual derivariam, como consequências necessárias, as demais regras, tal como havia proposto Leibniz. Este princípio denominou Teixeira de Freitas de a unidade superior através da qual podem ser deduzidas relações que compõem os institutos e as regras da legislação" (MARTINS- COSTA, 1999, p. 97).

${ }^{9}$ Nesse sentido, assim dispõe na própria Consolidação das Leis Civis: "Quantas leis entre nós não incorrerão desde logo em virtual e necessária revogação por se tornarem incompatíveis com as bases da Carta Constitucional?" (FREITAS, 1857, p. VIII)
} 
poderes, revelados em sua capacidade sistematizadora, alguns limites demonstram-se intransponíveis. Quem consolida não altera o direito, mas trabalha em sua atualização e em sua ordenação com padrões previamente estabelecidos. Apesar dessas confrontações, são esclarecedoras as palavras de Villela, ao elucidar a importância da interpretação e a liberdade presente no discurso hermenêutico. Segundo o autor, "como quer que seja, o comportamento de Teixeira de Freitas reforça a ideia de que não há consolidação rigorosamente neutra. Onde está o direito, aí está a interpretação. Onde está a interpretação, aí está a liberdade" (VILLELA, 1988, p. 250). Desse modo, os limites formais não foram obstáculos para uma atualização baseada no discurso da interpretação ${ }^{10}$.

Assim, devido a sua atualidade e a sua apuração técnica, a Consolidação das Leis Civis foi alçada ao patamar de um código civil. Importante, ainda, destacar que, no Brasil, um verdadeiro código civil ainda demandou alguns anos até ser concebido. Desse modo, de acordo com Sílvio Meira (1983, p. 74) “a Consolidação das Leis Civis do Brasil, de 1858 foi o verdadeiro Código Civil Brasileiro até primeiro de janeiro de 1916, quando se promulgou outro, baseado no projeto de Clóvis Beviláqua, para entrar em vigor a $1^{\circ}$ de janeiro de 1917. Foram, portanto, cerca de cinquenta e nove anos de vigência".

Todavia, apesar de a Consolidação das Leis Civis ser compreendida como verdadeiro Código Civil, a ratio presente em sua elaboração era a de ser um introito ao trabalho codificador. Como assinalado por João Baptista Villela consolidar é realizar uma "síntese de conciliação entre o passado e o presente, a consolidação poderá significar ato de aggiornamento do direito" (VILLELA, 1988, p. 253). Assim, o trabalho do consolidador Teixeira de Freitas objetivava garantir uma linha de continuidade histórica, permitindo a adequação do novo instrumento legislativo e a sua real eficácia ${ }^{11}$.

\footnotetext{
${ }^{10}$ Ainda segundo Villela, "não sendo o consolidador alguém que legisla, é natural que se guarde de formular livremente os textos que encontra. Mas seria reduzir de muito a utilidade de seu trabalho, atrelá-lo a expressão formal preexistente, não só porque muda o alcance dos preceitos, em virtude da incessante atividade legislativa, como também porque evolui o entendimento das regras, cuja expressão atualizada se busca precisamente alcançar. Haveria, portanto, uma dupla fonte de legitimidade para reproduzir o texto em linguagem reprocessada: adequar a determinação preceitual ao estado da legislação e conformá-la com o sentido vigente das regras de direito" (VILLELA, 1988, p. 252).

${ }^{11}$ Importante assinalar, ainda, que, devido ao sucesso alcançado pela sua consolidação, Teixeira de Freitas foi incumbido, em 1858, da elaboração do Código Civil brasileiro. Como resultado de seu encargo, foi desenvolvido o Esboço, trabalho extenso, composto por mais de 4900 artigos. Todavia, como relatado por Giordano Bruno Soares Roberto (2003, p. 65), "desgostoso pela demora dos trabalhos e pelo desprezo silencioso que sua obra recebeu, Freitas suspende a execução do contrato que, logo em seguida, é considerado resolvido pelo jurista e escritor José Alencar, então Ministro da Justiça". Não obstante seu insucesso, o Esboço teve uma severa influência nas legislações que o sucederam, bem como na elaboração das codificações de outros países sul-americanos.
} 


\section{CONSOLIDAÇÃO E CODIFICAÇÃO NA OBRA DE ANDRÉS BELLO}

O Código Civil da República do Chile foi promulgado em 14 de dezembro de 1855 e teve a sua origem nos trabalhos desenvolvidos pelo venezuelano Andrés Bello, ao longo de mais de vinte anos. Trata-se de uma codificação que, ainda hoje, permanece em vigor e que influenciou vários países latino-americanos, tais como Nicarágua, Colômbia, Equador e Uruguai (Cf. CALDERA, 1965, p. 143). Na referida obra, buscou-se conjugar as tradições jurídicas já existentes com as inovações trazidas pelo movimento de codificação vivenciado, principalmente, no continente europeu.

Andrés Bello nasceu em Caracas, morou por um longo período em Londres e, depois, veio a se estabelecer em Santiago do Chile ${ }^{12}$. Era um homem de múltiplos campos de atuação, dentre os quais se destacavam a educação, a universidade, a gramática, a literatura, a filosofia, as leis e a política. De acordo com Gregorio Weinberg (2010, p.12), “a abrangência de sua obra e a influência que ela nunca deixou de exercer conferiram a ele grande prestígio em todo continente latino-americano e explicam o fato excepcional de que, até os nossos dias, todos os falantes de língua espanhola o reivindiquem para si”.

Como parece natural, o processo de independência leva à necessidade de também se autonomizar a legislação nacional. Ocorre que, também no Chile, a ruptura não pôde ser feita de maneira abrupta, sendo mantida a vigência das normas da antiga metrópole em período posterior à emancipação política do país. Essa realidade parece confirmar as ideias de Henry Sumner Maine (1866, p. 42), para quem, "nas jovens nações, revela-se raro que a legislação seja chamada para a realização de uma reforma geral do direito privado. O clamor do povo não é pela mudança das leis, [...], mas somente pela sua pura, completa e fácil administração" ${ }^{13}$.

De acordo com Gregório Weinberg, diante do momento conturbado pelo qual passava a América Latina, Bello sustentava que "o objetivo não seria derrubar uma ordem

12 Rafael Caldera assim descreve a trajetória de Andrés Bello: "Conjunção feliz de duas épocas e de dois continentes, as circunstâncias históricas forjaram sobre uma natureza robusta a personalidade de Andrés Bello. Fruto sazonado da cultura colonial, amadurecido ao longo de vinte demorados anos à sombra do Museu Britânico, encontrou no Chile terreno amplo para deitar sua semente: e, assim sendo, a generosa oportunidade que lhe fora oferecida por aquele povo, em fase de serena criatividade, trouxe um campo definitivo ao seu trabalho" (CALDERA, 1965, p. 17).

${ }^{13}$ No original: "In the youth and infancy of a nation it is a rare thing for the legislature to be called into for the general reform of private law. The cry of the people is not for change in the laws, which are usually valued above their real worth, but solely for their pure, complete and easy administration" (MAINE, 1866, p. 42). 
ameaçada, e sim restaurá-la tão cedo quanto possível, utilizando instrumentos adequados: a educação, a legislação e o comércio" (WEINBERG, 2010, p. 15). Assim, também no Chile, em um determinado momento, propôs-se um preliminar trabalho de revisão do direito antigo em uma consolidação, para depois se alcançar uma codificação. Desse modo, diferentemente de Juan Egaña, que propunha uma reforma radical e completa do direito naquele país, implicando no abandono de soluções tradicionais e em sua troca por concepções novas, Andrés Bello esboçava uma notável preocupação com a preservação das tradições jurídicas então existentes. Essas ideias foram expostas em um artigo publicado no periódico chileno "El Araucano", no dia 28 de junho de 1933.

Bello defendia a divisão do processo de modernização legislativa em duas fases distintas: primeiramente deveria ser feita a consolidação (denominada no pensamento de Bello pela expressão codificación) e, só em seguida, deveria ser realizada a reforma, que materializaria o verdadeiro código civil $^{14}$. Sua construção teórica desenvolveu-se como reação às concepções de Egaña, buscando aproveitar os instrumentos legislativos anteriores, notadamente as Siete Partidas, principal fonte legislativa originária da antiga metrópole. Nesse sentido, Guzmán Brito (1988, p. 259) afirma que “así, pues, es paladina la distinción establecida por Bello entre reforma y codificación (consolidación): la primera, en síntesis, consistía en formar un cuerpo de derecho nuevo; la segunda, en formar un cuerpo nuevo pero de derecho previgente".

O referido intento foi visto como uma tentativa de agradar os setores conservadores da sociedade e do Congresso, que viam a ruptura como algo indesejável (Cf. JAKSIC, 2001, p. 194). Assim, a teorização construída por Bello revelou-se como apoio a um projeto de lei proposto pelo Deputado Manuel Camilo Vial, que indicava a compilação das leis existentes em um único corpo de direito. O referido projeto, no entanto, encontrou barreiras nas manobras parlamentares e, a partir do ano de 1834, foi esquecido pelo Legislativo chileno. O Ministro do Interior Diego Portales decidiu pedir que Bello começasse a redigir o Código Civil, tendo sido preparados, por ele, vários artigos sobre testamento e sucessões (JAKSIC, 2001, p. 195) $)^{15}$. Inicialmente, o papel desenvolvido por Bello não foi levado a público em

\footnotetext{
${ }^{14}$ Iván Jaksic afirma que Bello dava à palavra "codificación” a conotação de "compilación” (JAKSIC, 2001, p. 193).

${ }^{15}$ Para maiores detalhes sobre o processo político que redundou na escolha de Andrés Bello para a elaboração do Código Civil da República do Chile, ver: GUZMÁN BRITO, 1988, p. 256-260 e JAKSIC, 2001, p. 190-196.
} 
decorrência das objeções que sofria seu nome, principalmente, pelos fatos de ser estrangeiro e de não possuir título em Direito ${ }^{16}$.

A morte de Diego Portales (1837) e a Guerra contra a Confederação Peru-Boliviana (1837-1839) atrasaram as atividades de codificação. No entanto, quando a situação nacional apresentou melhoras, Bello, como senador e autor de partes importantes da nova legislação, estava em uma posição muito mais forte para reavivar a tarefa de codificação (JAKSIC, 2001, p. 196). Em 10 de agosto de 1840, foi proposta a formação de uma comissão bicameral que daria origem ao Código Civil chileno. Mesmo com dificuldades, Bello entregou ao governo seu primeiro rascunho completo da codificação, em outubro de 1852 (JAKSIC, 2001, p. 197) e, em 1855, o projeto foi aprovado no Congresso e promulgado pelo Presidente da República. O Código entrou em vigor em $1^{\circ}$ de janeiro de 1857 (JAKSIC, 2001, p. 202).

Apesar de a prática concretizada por Andrés Bello não ter seguido a sua teorização de uma prévia e autônoma consolidação das leis que, até então, estavam em vigência, percebe-se, um alinhamento com os trabalhos desenvolvidos por Teixeira de Freitas. Na teorização de Bello, o emprego da técnica consolidadora apresenta-se como fase preliminar de feitura de uma codificação, no intuito de se preservar a tradição jurídica anterior. Como assinalado por Guzmán Brito (1988, p. 266), a originalidade não está no mero emprego da consolidação como fase preliminar à codificação, mas, sim, na deliberada divisão do processo de renovação jurídica em duas partes distintas. Na obra dos aludidos juristas é possível perceber a consciente manifestação de dividir a reforma em fases com o intuito de preservação da tradição jurídica. Nesse sentido, assinala o autor:

La primera conclusión que se impone con relieves muy salientes, es que la bipartición del proceso codificador en una consolidación primero y en una codificación propiamente tal después no ha sido algo original en Chile ni en Brasil, pues se trata de una operación global de antecedentes europeos. Pero inmediatamente salta a la vista que la exposición de una teoría o doctrina sobre aquella bipartición, esto es, la explícita y consciente manifestación de la idea de dividir el proceso de renovación jurídica en dos etapas, una meramente técnica y otra de fondo, ha sido formulada con ribetes muy nítidos en Chile e después en el Brasil. En efecto, no encontramos en la literatura europea una exposición similar a la de Bello o Teixeira, en que tan tajantemente se apunte la bipartición (GUZMÁN BRITO, 1988, p. 266).

\footnotetext{
${ }^{16}$ Iván Jaksic (2001, p. 192) afirma que "para solucionar este segundo problema, Andrés Bello solicitou o grau de bacharel em Direito Civil e Canônico à Universidad de San Felipe. O grau foi outorgado por meio de exames ante os membros acadêmicos e Bello não teve qualquer dificuldade para obter o título neminem discrepante" (Tradução livre).
} 
Não obstante a existência de tal similitude e a constatação da originalidade de ambos, Guzmán Brito é categórico ao asseverar que uma influência de Bello sobre Teixeira de Freitas deve ser descartada, pois, dificilmente, este último teria tido acesso aos textos de Bello que tratavam do tema (Cf. GUZMÁN BRITO, 1988, p. 262), restringindo sua análise apenas às concepções presentes na codificação chilena.

Além disso, deve ser destacado que, apesar de não se verificar a referida autonomia do emprego da técnica consolidadora, a nova codificação tem por característica basilar a preservação das anteriores tradições jurídicas, dando-se preferência sempre à utilização de partes dos textos das Siete Partidas, em detrimento da simples apropriação de dispositivos presentes em códigos civis, então vigentes ${ }^{17}$. Esse fato, de certa maneira, revela que o Código Civil chileno buscou congregar os novos valores e a necessidade de adequada ordenação com uma importante preocupação relativa à manutenção de institutos e concepções já existentes. Nas palavras de Guzmán Brito (1982, p. 454):

\footnotetext{
El código no fue sólo un producto técnico, como obra legislativa destinada a señalar dirección y sentido a las actuaciones humanas, también un modelo absorbente de ideas sobre organización social. Igualmente en esto vinculó se él con el moderno movimiento codificador, que aspiraba non sólo a la reformulación técnica de la legislación y el derecho, sino además a su reforma de fondo, mediante la inserción de ciertas ideas en la legislación que nuevamente se formara.
}

Essa congregação de ideias marca a codificação chilena e, de certo modo, revela a sua originalidade. A preocupação com o passado e com as tradições revela-se como ponto essencial no desenvolvimento de um Código Civil, pois a ruptura abrupta com uma ordem jurídica pré-estabelecida não se demonstra como técnica adequada, devendo a mudança da legislação ser precedida de uma adequada reflexão social sobre os anseios com relação àquele instrumento. A técnica consolidadora pode ser de grande valia no processo de concepção de um código civil, porém, como visto, deve ser salientado que o seu uso não se apresenta como único caminho para o alcance de uma aplaudida codificação, como demonstra o exemplo chileno.

\footnotetext{
${ }^{17}$ Sobre as influências do codificador chileno, Engênio Faccini Neto (2013, p. 77) sustenta: "Andrés Bello inspirou-se não só no modelo francês, mas também nas tradições jurídicas romanas (o projetista referiu-se várias vezes às Siete Partidas e ao pensamento de Savigny), além de desenvolver ideias originais para a época, como a propriedade fiduciária".
} 


\section{RFD}

CONCLUSÃO

Como visto, não é assente a delimitação das diferenças existentes entre o emprego da técnica codificadora e da técnica consolidadora. Impera, no entanto, a teoria exposta por Mario Viora, que estabelece que o ponto central de distinção das figuras estaria na originalidade do conteúdo identificado nas codificações, enquanto nas consolidações haveria uma limitação à ordenação do direito pretérito. Vê-se, assim, que, por tal concepção, é a sistematização imbuída de direito novo o elemento propulsor, responsável por romper com a antiga tradição europeia de feitura de consolidações.

Não obstante as discussões teóricas acerca dos institutos em análise, é possível verificar que os fenômenos da consolidação e da codificação podem tomar caminhos próprios não adstritos às conceituações estanques formuladas pela doutrina. E é justamente a liberdade de construção dada ao jurista que possibilita a realização de novos desenhos, dotados de notável originalidade.

Na América do Sul, a concepção sobre a utilização de consolidações de leis civis tem como maiores expoentes Augusto Teixeira de Freitas e Andrés Bello. Ambos idealizaram a utilização da técnica consolidadora com objetivos diversos dos apresentados nos compêndios doutrinários. Para os dois juristas, a consolidação deveria ser apresentada como exercício preparatório para a elaboração de uma codificação. A intenção central da tarefa de consolidar estaria na manutenção de uma tradição jurídica já existente, não permitindo uma ruptura com o sistema jurídico anterior, geradora de um ambiente de extrema insegurança jurídica.

Não obstante essa característica similar no uso da técnica da consolidação, os dois juristas empreenderam seus trabalhos de maneira diversa. Enquanto Teixeira de Freitas elaborou a Consolidação das Leis Civis (1857) como etapa preparatória para a codificação, Andrés Bello caminhou em sentido oposto, elaborando o Código Civil diretamente, mas tentando preservar parte dos textos que, até então, eram vigentes. Percebe-se, assim, que a concepção do que deveria ser uma consolidação apresenta-se como ponto comum em plano teórico, mas dissonante se tomada em consideração a forma como foi empreendida a aludida tarefa pelo codificador chileno. Por outro lado, não se pode negar que, nas duas experiências, revela-se presente uma acentuada preocupação com a necessidade de se preservar as antigas tradições jurídicas, sem que fossem apropriadas unicamente influências 


\section{RFD}

legislativas estrangeiras, evitando, por conseguinte, uma brusca quebra em seus respectivos ordenamentos.

\section{REFERÊNCIAS}

CAENEGEM, R. C. van. Uma introdução histórica ao direito privado. 2. ed. Trad. Carlos Eduardo Lima Machado. São Paulo: Martins Fontes, 2000.

CALDERA, Rafael. Andrés Bello. 4. ed. Trad. Maria Helena Lima Senise. Caracas: Instituto Nacional de Cultura y Bellas Artes, 1965.

CANARIS, Claus-Wilhelm. Pensamento sistemático e conceito de sistema na ciência do direito. 3. ed. Trad. A. Menezes Cordeiro. Lisboa: Calouste Gulbenkian, 2002.

FACCHINI NETO, Eugênio. Code Civil francês: gênese e difusão de um modelo. Revista de Informação Legislativa, Brasília, n. 198, abril-junho, 2013.

GILISSEN, John. Introdução histórica ao direito. 5. ed. Trad. A. M. Hespanha e L. M. Macaísta Malheiros. Lisboa: Calouste Gulbenkian, 2008.

GUZMÁN BRITO, Alejandro. Codificación y consolidación: una comparación entre el pensamiento de A. Bello y el de A. Teixeira de Freitas. Augusto Teixeira de Freitas e il diritto latinoamericano. Org. Sandro Schipani, Padova: CEDAM, 1988.

GUZMÁN BRITO, Alejandro. Andrés Bello codificador: historia de la fijación y codificación del derecho civil en Chile. Tomo I. Santiado de Chile: Ediciones de la Universidad de Chile, 1982.

JAKSIC, Iván. Andrés Bello: la pasión por el orden. Santiago de Chile: Fundación Ignacio Larramendi, 2001.

LORENZETTI, Ricardo Luis. Fundamentos do direito privado. Trad. Vera Maria Jacob Fradera. São Paulo: Revista dos Tribunais, 1998.

MAINE, Henry Sumner. Ancient law: its connection with the early history of society and its relation to modern ideas. 3. ed. London: John Murray, 1866.

MARTINS-COSTA, Judith. O sistema na codificação civil brasileira: de Leibniz a Teixeira de Freitas. Revista del Centro de Investigaciones de Filosofía Jurídica y Filosofía Social, Rosario, v. 23, 1999.

MEIRA, Silvio. Teixeira de Freitas: o jurisconsulto do império. Rio de Janeiro: José Olympio, 1983. 
PECORELlA, Corrado. Consolidazione e codificazione in uma esperienza brasiliana. Augusto Teixeira de Freitas e il diritto latinoamericano. Org. Sandro Schipani, Padova: CEDAM, 1988.

PEREIRA, Caio Mário da Silva. Instituições de direito civil. Vol. I. Introdução ao direito civil: teoria geral do direito civil. 23. ed. Rio de Janeiro: Forense, 2010.

PETRONIO, Ugo. Una categoria storiografica da rivedere. Quaderni fiorentini per la storia del pensiero giuridico moderno, Milano, v. 13, p. 705-719, 1984.

ROBERTO, Giordano Bruno Soares. Introdução à história do direito e da codificação: uma análise do novo código civil. Belo Horizonte: Del Rey, 2003.

VILLELA, João Baptista. Da Consolidação das leis civis à teoria das consolidações: problemas histórico dogmáticos. Augusto Teixeira de Freitas e il diritto latinoamericano. Org. Sandro Schipani, Padova: CEDAM, 1988.

VIORA, Mario E. Consolidazioni e codificazioni: contributo alla storia della codificazione. 3. ed. Torino: Giappichelli, 1967.

WEINBERG, Gregório. Andrés Bello. Recife: Editora Massangana, 2010.

WIEACKER, Franz. História do direito privado moderno. 3. ed. Trad. A. M. Botelho Hespanha. Lisboa: Calouste Gulbenkian, 2004. 